\title{
Lords a-leaping: the Soulsby report on antimicrobial drug resistance
}

'Lords lead fight against killer bugs' proclaimed the press release from the House of Lords Press Information Office. The media duly took up the story, which appeared as the lead item on the BBC morning news; erudite editorials appeared in the broadsheets. The cause of this furore was the publication of a House of Lords Select Committee report.

In 1997 the Science and Technology Committee of the House of Lords in the UK convened a Sub-Committee under the chairmanship of Lord Soulsby of Swaffham Prior (Emeritus Professor of Animal Pathology, University of Cambridge) to conduct an inquiry into the rise in resistance to antibiotics and other antimicrobial agents, and its implications for UK and international policy. The subcommittee published its report in April 1998 [1,2] and it has been made available on the internet (http://www.parliament.uk). The enquiry followed an earlier report by the Parliamentary Office of Science and Technology in 1994 [3].

The Lords' enquiry team appointed expert scientific advisers, took evidence widely and invited written submissions on all aspects of the topic. Various key locations were visited, including the Public Health Laboratory Service (PHLS) headquarters and King's College Hospital, London. Several members of the committee held discussions at institutions in the USA, including the Centers for Disease Control and Prevention in Atlanta, the National Institute for Allergy and Infectious Diseases in Washington, and the US Food and Drug Administration. All the oral and written evidence gathered by the Soulsby Committee has also been published in a separate volume [4]. It has not been posted on the internet but contains a wealth of information and articulates the opinions of many professional bodies and individuals. In some ways it is as interesting and revealing as the report itself.

The Soulsby report highlights many of the concerns expressed by those submitting evidence, notably: the crucial importance of educating young (and not so young) doctors in good prescribing habits; the role of microbiologists and control of infection teams in the prevention of infection (the 'Cooke report' on hospital infection control [5] is singled out for praise); the need for comprehensive surveillance of resistance trends in human and veterinary practice; the importance of controlling over-the-counter availability of antibiotics; and the global dimension of the resistance problem. The Lords also warn of the dangers of complacency, call for a campaign of public education so that the limitations of antimicrobial drug treatment and the need for prudence are more generally recognised, and point to the continuing threat to human health from the excessive use of antibiotics in animals. The role of the pharmaceutical industry is examined and concerns about deficiencies in resistance surveillance are expressed. The requirement for adequate resources to address many of the unanswered questions about the way antibiotic resistance develops, to carry out adequate monitoring with good denominator data, and to support the global efforts of the WHO, are stressed. The report ends by urging the Government to develop a strategy to safeguard the effectiveness of antimicrobial agents and to back the strategy with resources.

All this is well and good, and certainly to be welcomed. Never before has a parliamentary body spoken out so boldly on this problem. The language is clear, pointed and judicious; the Lords were alarmed by what they found and spoke their mind. However, the report has certain weaknesses. Agents other than antibacterial drugs are dealt with somewhat cursorily - there is a short section on resistance in viruses and malaria parasites get a passing mention, but other protozoa and fungi are scarcely mentioned at all. Consideration of the impact of the use of anthelminthic and other antiparasitic agents is restricted to the problems of nematodes and scab in sheep. Similarly, sections of the report on the international dimension of antimicrobial drug resistance are relatively muted, although the worldwide problems with multi-drug-resistant tuberculosis do receive attention. These shortcomings are not surprising given the concerns about resistance in certain bacterial pathogens, and the need to take account of international sensibilities, but they mean 
that certain important aspects of the global problem received less than their due.

Antimicrobial drug resistance has moved up the political agenda in the UK to the extent that it has not only stimulated a House of Lords Select Committee, but is also under active consideration by the Government's Standing Medical Advisory Committee and the Advisory Committee on the Microbiological Safety of Food. Resistance features among the Chief Medical Officer's concerns and is the subject of one of the PHLS's major programmes. Whether this burst of interest will translate into any productive action remains to be seen. But whatever happens in the UK, where regulation is generally effective and attitudes to antibiotic usage mainly sensible (although still with scope for considerable improvement), serious problems will continue to exist throughout the world unless international collaborative action is undertaken to regulate more effectively the manufacture, availability and promotion of antimicrobial drugs worldwide, and to educate prescribers and the public in their careful use.

Concerns about resistance have been raised at regular intervals during the last 40 years or more [6-9], but global awareness of the antimicrobial drug resistance problem has never been greater than it is today. For the first time there is near consensus that effective action needs to be taken before it is too late. However, if this is to be a defining moment in the fight to turn the tide of drug resistance, it is not sufficient to appeal to prescribers, farmers, manufacturers and consumers to mend their ways; there will have to be international action from governments as well.

D. GREENWOOD Division of Microbiology and Infectious Diseases, School of Clinical Laboratory Sciences, University Hospital, Queen's Medical Centre, Nottingham NG7 2UH E-mail: david.greenwood@nottingham.ac.uk

\section{References}

1. Report of the Select Committee on Science and Technology of the House of Lords. Resistance to antibiotics and other antimicrobial agents. London, The Stationery Office. 1998.

2. Hawkey PM. Action against antibiotic resistance: no time to lose. Lancet 1998; 351: 1298-1299.

3. Border P. Diseases fighting back - the growing resistance to TB and other bacterial diseases to treatment. London, Parliamentary Office of Science and Technology. 1994.

4. Evidence presented to the Select Committee on Science and Technology of the House of Lords. Resistance \& antibiotics and other antimicrobial agents. London, The Stationery Office. 1998.

5. Report. Hospital infection control. Guidance on the control of infection in hospitals. London, Department of Health and Public Health Laboratory Service. 1995.

6. Wolstenholme GEW, O'Connor CM (eds). Drug resistance in micro-organisms. London, J and A Churchill. 1957.

7. Anonymous. Saving antibiotics from themselves. Nature 1981; 292: 661 .

8. Cohen ML. Epidemiology of drug resistance: implications for a post-antimicrobial era. Science 1992; 257: 1050-1055.

9. Kunin CM. Resistance to antimicrobial drugs-a worldwide calamity. Ann Intern Med 1993; 118: 557-561. 